\title{
STATISTICAL CONTROL OF PROCESS OF FLASH-BUTT WELDING OF RAILS. TWO-LEVEL CONTROL SYSTEM
}

\author{
S.I. KUCHUK-YATSENKO, P.M. RUDENKO, V.S. GAVRISH, A.V. DIDKOVSKY and E.V. ANTIPIN \\ E.O. Paton Electric Welding Institute, NASU \\ 11 Kazimir Malevich Str., 03680, Kiev, Ukraine. E-mail: office@paton.kiev.ua
}

\begin{abstract}
The article deals with the modern approach to creation of system for control of process of flash-butt welding of rails based on statistical analysis of data collection, characterizing this process. In the received data such an analysis allows detecting a number of previously unknown and useful knowledge interpretations (knowledge discovery in databases), required for making decision on the process control. The analysis of causes was carried out which may lead to deviations in the course of technological process and, as a consequence, to violation of the quality of welded butts. To detect these disturbances, two-level control system was proposed. At the lower level in the system of direct digital control the traditional quality control of welded joints is used for «instantaneous» response to the occurrence of rejection and prevention of its further spreading. At the upper level (at the diagnostic center of Company «Ukrzaliznytsya») the statistical processing of welding rails protocols is carried out to detect disturbances which are difficult to control by direct measurements. The developed algorithms passed an experimental verification and can be recommended for their further introduction into industry. 5 Ref., 1 Table, 4 Figures.
\end{abstract}

Keywords: flash-butt welding, two-level control system, control of process parameters, statistical control, technical state of equipment, allowance control

The modern control systems of the FBW process of rails, installed in all the PWI-designed welding machines of new generation, allow measuring and calculating the basic parameters of the process, which allow judging about the quality of welded butt with a certain degree of validity. These data in the form of a protocol of welding butt are actually its certificate. The obtained protocols are stored within the whole period of operation of welded joints in the railroad track and form the significant arrays of information, which, except of the acceptance certificate of the product for operation, can be used to reveal disturbances influencing the welding process, but are not subjected to the methods of direct measurement. The similar methods of information processing, so-called data mining, the intellectual data analysis, profound data analysis are used for detection of previously unknown, non-trivial, practically useful and accessible interpretations of knowledge in the data required for making decision in different areas of human activity.

The use of the well-known methods of statistical processing of information by butts, collected during the certain time periods in one and the same machines, the complex of machines of a one rail welding enterprise (RWE) or a branch as a whole, allow optimizing the operating conditions of welding machines and the control of welded rails production in general.
For this aim at the PWI the two-level system was developed. On the lower level in the system of direct digital control the traditional quality control of welded joints for «instantaneous» response in real-time to the occurrence of rejection is used to prevent its further spreading.

Further, the information on welded butts is transferred from the welding machines of RWE to the upper level - diagnostic center. At the diagnostic center the statistical processing of rail welding protocols is carried out to detect disturbances which are difficult to control by direct measurements. For example, unsatisfactory performance of auxiliary operations on preparation of rails before welding, deviation of physical and chemical properties of rails metal, unsatisfactory observing of technological operations by service personnel or unsatisfactory industrial conditions (Figure 1).

Taking into account the capabilities of existing local systems for process control, the developed system, except of direct digital control of welding process, performs the following functions:

- prediction of quality of welded butt according to the process parameters using more advanced algorithms with the possibility of involvement of qualified specialists for prediction in special cases; 


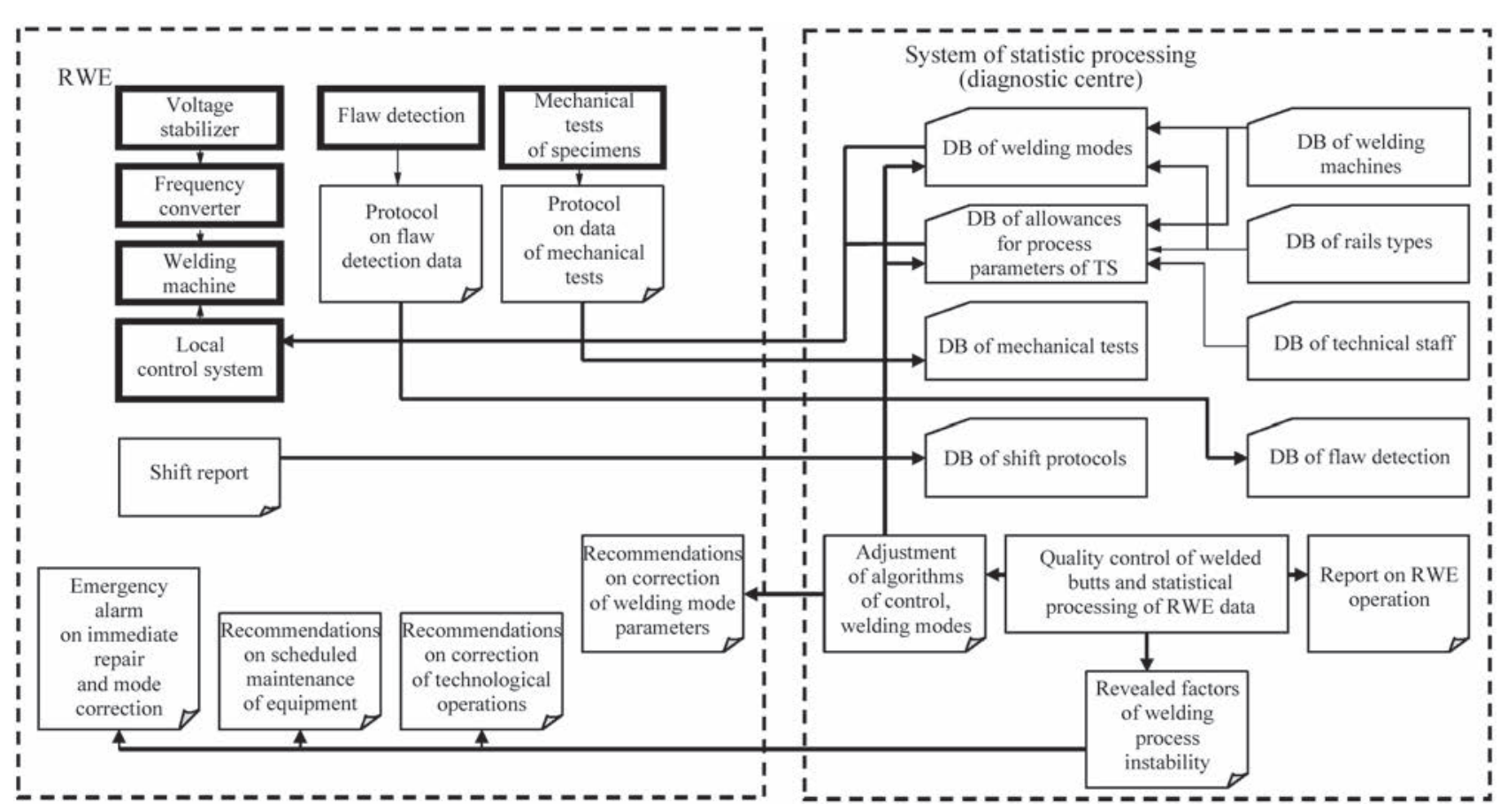

Figure 1. Block diagram of two-level control system

- control of technical state of welding equipment, elaboration of recommendations and planning of its maintenance;

- detection and recognition of emergency situations for immediate intervention into the technological process;

- detection of systematic deviations and trends of process parameters, which may result in deterioration of the quality values of welded joints, elaboration of recommendations on correction of welding parameters.

For FBW of rails in the stationary and mobile welding machines the following causes can be distinguished, which may result in deviations in the course of technological process and, as a consequence, violation of welded butts quality [1-3]:

- unsatisfactory performance of auxiliary operations on preparation of rails before welding: edges preparation, cleaning the rails surface at the places of current supply and postweld treatment of butts - machining of rails surface during flash removal;

- deterioration of technical state of welding equipment, for example, increase in welding circuit resistance of the machine;

- defects in the base metal of rail steel;

- unsatisfactory keeping the technological operations by welder (poor cleaning and alignment of rails before welding);

- unsatisfactory industrial conditions: inadmissible changes of ambient temperature and mains voltage;

- unfavorable combination of process parameters, even when these parameters are in the range of al- lowances, for example, decrease in mains voltage and increase in welding circuit resistance of the machine.

To detect the described disturbances the algorithm of statistical processing of the data of the process parameters was developed, at which the arrays of protocols of welding butts are processed with their separation and grouping according to the relevant characteristics (the Table).

During welding process the following information is formed in real time (Figure 2):

1. In welding of butts according to the measured values of parameters of the welding process $x_{1}-x_{12}$ using the control algorithm based on «fuzzy» logic [4] the quality value of welded joint, i.e. the probability of its compliance with the requirements of the Technical Specifications, is calculated. The obtained data are formed in the arrays according to the number of machine, surname of welder, serviceman, flaw detection engineer and the team on performance of auxiliary operations (preparation of rails before welding and postweld treatment of butts), by correction of welding mode for displacement of distribution of random values of the mentioned measurements to the center of the allowance interval.

2. According to the data of ultrasonic flaw detection (UFD) the presence of cracks, lacks of penetration, dull spots, etc. is checked in each welded butt, these data are recorded in the UFD databases. The quality of machining of welded butt after flash removal is also visually checked. The information on the presence of defects is immediately provided to the welder and to the shift serviceman. The defective butt is cut out. The mentioned functions are carried out 
Separation of welding butts protocols for detecting different disturbances violating the technological process

\begin{tabular}{|c|c|c|c|c|}
\hline $\begin{array}{l}\text { Cause for arising violation } \\
\text { in the technological process } \\
\text { for welding rails }\end{array}$ & $\begin{array}{l}\text { Identification } \\
\text { parameter }\end{array}$ & $\begin{array}{l}\text { Sampling } \\
\text { volume }\end{array}$ & $\begin{array}{c}\text { Parameter } \\
\text { of arrays separation }\end{array}$ & $\begin{array}{l}\text { Influence } \\
\text { parameter }\end{array}$ \\
\hline $\begin{array}{l}\text { Auxiliary operations on prepara- } \\
\text { tion of rails before welding and } \\
\text { postweld butt treatment }\end{array}$ & $\begin{array}{l}Z_{\text {sh.-c }} \text {, visual data on } \\
\text { postweld butts ma- } \\
\text { chining }\end{array}$ & $1-2$ shifts & $\begin{array}{l}\text { Full name of shift } \\
\text { serviceman + RWE }\end{array}$ & Methods and equipment \\
\hline $\begin{array}{l}\text { Technical state of welding equip- } \\
\text { ment }\end{array}$ & $\begin{array}{l}T_{\text {w }}, U_{\mathrm{h}}, U_{\mathrm{l}}, V_{\text {flash }}, v_{\text {forc }}, \\
V_{\text {ups }}, S_{\text {tot }}, S_{\text {ups }}, Z_{\text {sh.-c }}\end{array}$ & $1 / 3-1$ month & $\begin{array}{l}\text { Number of welding } \\
\text { machine }\end{array}$ & Maintenance, repair \\
\hline $\begin{array}{l}\text { Physical and chemical properties } \\
\text { of rails metal }\end{array}$ & $\begin{array}{l}L_{\mathrm{b}}, F_{\mathrm{fr}}, \text { data on flaw } \\
\text { detection }\end{array}$ & $\begin{array}{l}\text { Immediately during } \\
\text { detection or } 1 \text { shift }\end{array}$ & $\begin{array}{l}\text { Number of batch, rails } \\
\text { grade, Number of } \\
\text { machine }\end{array}$ & Mode correction \\
\hline $\begin{array}{l}\text { Technological operations of } \\
\text { welder }\end{array}$ & $\begin{array}{l}T_{w}, T \text { between welding } \\
\text { and flashing of obliqui- } \\
\text { ty, } Z_{\text {sh.-c }} \text {, slipping }\end{array}$ & $\begin{array}{l}\text { Immediately during } \\
\text { detection or } 1 \text { shift }\end{array}$ & Full name of welder & $\begin{array}{l}\text { Methods (industrial in- } \\
\text { structions) }\end{array}$ \\
\hline $\begin{array}{l}\text { Control of the process of welding } \\
\text { specimens and UFD }\end{array}$ & $L_{\mathrm{b}}, F_{\mathrm{fr}}$, UFD data & 1 shift & $\begin{array}{l}\text { Full name of welder, } \\
\text { UFD engineer }\end{array}$ & Methods and equipment \\
\hline Industrial conditions & $U_{\mathrm{h}}, U_{\mathrm{l}}, v_{\text {flash }}, v_{\text {forc }}, v_{\text {ups }}$ & $1-2$ months & RWE & Stabilization of $U_{\text {ains }}$ or $T_{\text {oil }}$ \\
\hline $\begin{array}{l}\text { Unfavorable combination of pro- } \\
\text { cess parameters }\end{array}$ & $\begin{array}{l}\text { Fuzzy algorithm of } \\
\text { control and monitoring }\end{array}$ & $\begin{array}{l}\text { Immediately during } \\
\text { detection or } 1 \text { shift }\end{array}$ & Number of rail section & $\begin{array}{l}\text { Correction of welding } \\
\text { mode }\end{array}$ \\
\hline
\end{tabular}

beyond the control system, the entry of UFD data is carried out manually.

3. At the beginning, in the middle and the end of the shift the welding of rail specimens and mechanical tests are carried out. The tests data, namely bending deflection $L_{\mathrm{b}}$ and fracture force $F_{\mathrm{fr}}$ are compared with the preset values. If the obtained values are lower than the preset ones, the welding and testing of additional specimens is carried out to detect the reliability of inadmissible deviation. During confirmation of inadmissible deviation of the process the correction of welding mode is carried out. The obtained data are used to adjust the model of welding quality control. The mentioned functions are carried out beyond the control system, the entry of the results of mechanical tests of specimens is carried out manually.

Beyond the time of technological process the following information is formed:

4. To control the technical state of welding machine, the data on sections of one and the same grade of rails welded in one and the same machine are unified in the protocol of technical state of welding machine. The time of response, and thus, the average time can be significant: from one to several shifts. It is obvious that in case of emergency situation the information on repair is supplied immediately.

5. To control the industrial conditions the statistical evaluations of welding at one and the same modes and in one and the same type of machine of each RWE are combined. According to voltage $U_{\mathrm{f}}$ and $U$ h the stability of power mains and according to the speeds $v_{\text {flash }}$, $v_{\text {forc }}$ and $v_{\text {ups }}$ the stable operation of hydraulic drive are determined, which, in its turn, is connected with the temperature of the environment and its influence on the properties of hydraulic system fluid. The comparison of these evaluations at different RWE can serve as a basis for taking measures to improve the industrial conditions.

6. To specify the allowances for the control of the process the statistical data for all RWE are unified for each grade of rails and the corresponding welding mode.

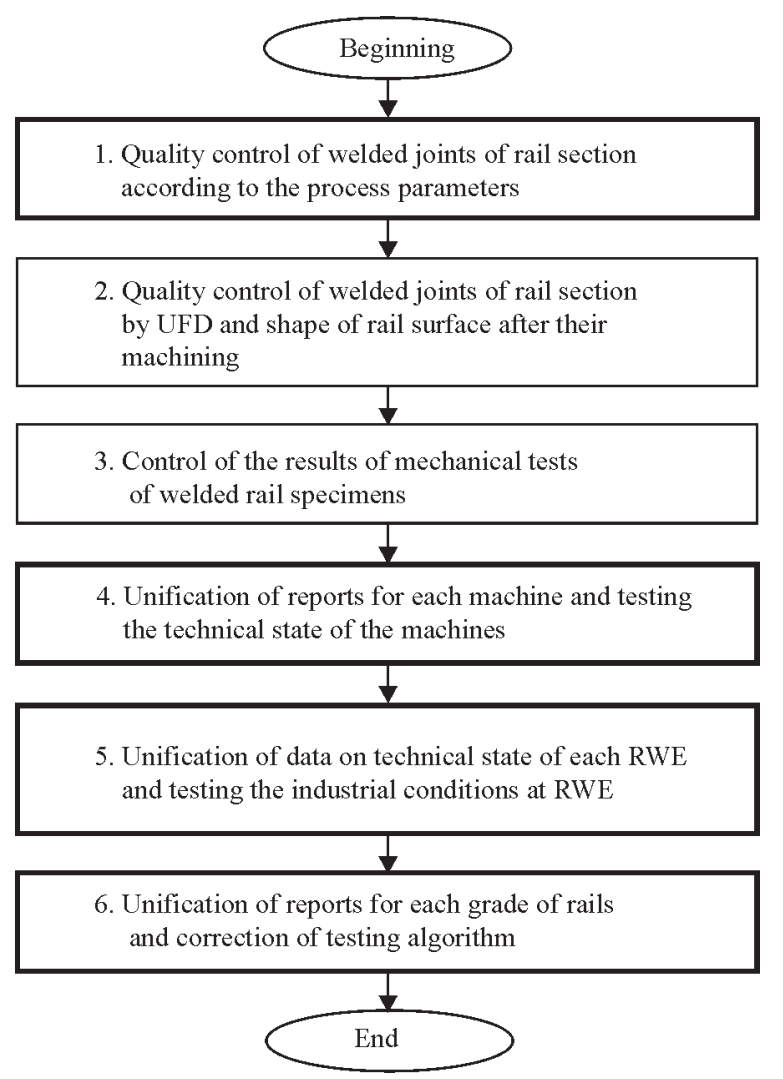

Figure 2. Algorithm for the rail welding process monitoring (operations are distinguished which are automated in the computer control system) 


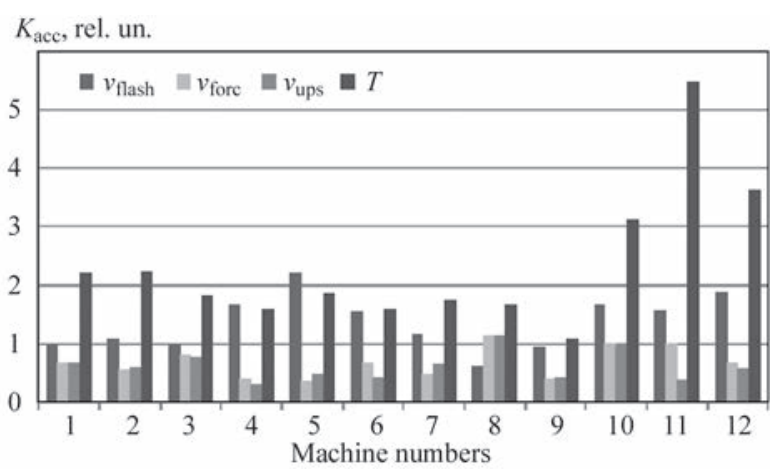

Figure 3. Coefficients of accuracy $K_{\text {acc }}$ of parameters grouped according to machines

In the statistical analysis the distribution of random values of welding process parameters were evaluated according to their average value and the mean square deviation. For easy comparison of different parameters these values were further considered in the relative units in the form of so-called coefficients of accuracy $K_{\text {acc }}$ and adjustment $K_{\text {adj }}$ [5]:

$$
K_{\text {acc }}=6 S_{\text {msd }} / \delta ; \quad K_{\text {adj }}=\left(X_{\text {av }}-X_{0}\right) / \delta,
$$

where $S_{\mathrm{msd}}, X_{\mathrm{av}}$ is the mean square deviation and the average value of distribution of values of the welding process parameter; $\delta$ is the parameter allowance; $X_{0}$ is the middle of the tolerance field or the preset parameter value.

For analysis of deviations it is necessary to take into account that some controlled parameters (e.g. $\left.S_{\text {flash }}, U_{1}, U_{2}, U_{3}, L_{\text {ups }}, P_{\text {ups }}, T_{\text {ups } 1}\right)$ are preset by direct method in the control system, and the errors in their reproduction are related to the accuracy of operation of the equipment and, in particular, of the control system.

At the same time, the other parameters $\left(v_{\text {flash }}, T_{\mathrm{w}}\right.$, $\left.v_{\text {forc }}, v_{\text {ups }}\right)$ are preset indirectly. The errors of reproduction of these parameters are connected both with the condition of welding equipment as well as with the coarse of the technological process.

As an example of system operation, let us consider the data on the accuracy coefficient for 12 welding machines of 4 RWE of the branch at number of welded butts of about 30,000.

According to the indirectly preset parameters (Figure 3$)$ it is seen that 3 machines $(10,11$ and 12) have a sharp difference in the data on time of welding. These machines belong to one RWE, and it was natural to suggest some general deviation in the process charac-

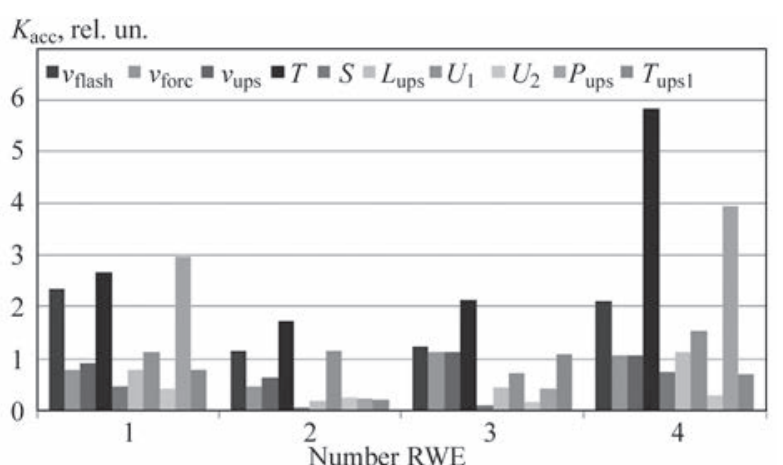

Figure 4. Coefficients of accuracy $K_{\text {acc }}$ of parameters grouped according to RWE

teristic to this RWE. The additional analysis directly at the enterprise revealed differences in the technology of rails edges preparation before welding as compared to other RWE.

The data on the accuracy coefficient for the parameters, grouped by RWE, revealed that the hydraulic pump stations at different RWE $\left(P_{\text {ups }}\right.$ parameter $)$ differ greatly as to their technical state and require additional checking (Figure 4).

It is obvious that except of the technical problems the described algorithm affects organizational problems of the whole production of welded tracks and should be not only specified as to experimental operation of the control system, but first of all agreed with the management of track facilities service.

\section{Conclusions}

The two-level control system was developed and the statistical processing of results of allowance control of quality of rail butts welded during the recent years at the enterprises of «Ukrzaliznytsya» was performed. The obtained results revealed new opportunities for improvement of the quality stability of welded joints.

1. Kuchuk-Yatsenko, S.I. (2008) Influence of structure heredity of low-alloy and carbon steels on weldability in solid phase, Vol. 1, 148-165. Kiev: Akademperiodika.

2. Gudkov, A.V., Nikolin, A.I. (2012) Specifics of welding of modern rails. Put i Put. Khozyajstvo, 4, 9-13.

3. (2011) Improvement of efficiency and reliability of rails: Transact. of VNIIZhT. Ed. by A.Yu. Abdurashitov. Moskow: Intekst.

4. Kruglov, V.V., Dli, M.I. (2002) Intelligent information systems: Computer support of fuzzy logic and inference. Moscow: Fizmatlit.

5. R 60-601-20-91: Recommendations on assessment of accuracy and stability of technological processes (equipment). Moscow: VNIIS Gosst. Rossii. 